\title{
A single-institution study of so-called "non-secreting" intracranial germinomas: neurological characteristics, treatment procedures, and clinical outcomes
}

\author{
Jiajun Zhou \\ Capital Medical University Sanbo Brain Hospital \\ Ting Lei \\ Capital Medical University Sanbo Brain Hospital \\ Jinyi Zuo \\ Capital Medical University Sanbo Brain Hospital \\ Chenxing Wu \\ Capital Medical University Sanbo Brain Hospital \\ Rui Liu \\ Capital Medical University Sanbo Brain Hospital \\ Shouwei Li ( $\sim$ lishouwei@ccmu.edu.cn ) \\ Capital Medical University Sanbo Brain Hospital https://orcid.org/0000-0003-0336-403X
}

\section{Research Article}

Keywords: CNS, germinoma, histological diagnosis, tumor marker, surgery, biopsy

Posted Date: February 7th, 2022

DOI: https://doi.org/10.21203/rs.3.rs-1004665/v2

License: @ (i) This work is licensed under a Creative Commons Attribution 4.0 International License. Read Full License 


\section{Abstract}

\section{Background and Purpose}

Intracranial germinomas are rare brain tumors. In the present study, we collected data of patients with histology-proven germinomas, and analyzed their neurological characteristics, treatment procedures, and clinical short-term outcomes.

\section{Methods}

We reviewed the data of patients with "non-secreting" intracranial germinomas from January 2012 to June 2021 in our institution from Beijing, China.

\section{Results}

There were 162 (69.8\%) male patients and 70 (30.2\%) female patients. Pineal germinomas were mainly found in male patients (98.3\%), and germinomas in sellar/suprasellar region were often observed in female patients (67.5\%). The most common clinical presentations were polyuria/polydipsia (42.7\%), headache (40.5\%), visual disturbance (37.5\%), and motor impairment (28.4\%). The symptoms of endocrinological alteration had significantly longer duration before hospital admission. Patients with pure germinoma had a higher serum beta-human chorionic gonadotropin ( $\beta-H C G$ ) level than the germinoma with syncytiotrophoblastic giant cells (STGCs) ( $P=0.001)$, and no significant difference was noted in serum alpha-fetoprotein (AFP) level between the two groups $(P=0.540)$. Tumors with multiple lesions such as bifocal and multifocal diseases had a higher tendency to intracranial dissemination and spinal seeding at diagnosis $(P<0.001$ and $P<0.001$, respectively). The mean duration of open craniotomy was 268.8 min with an average volume of blood loss of $316.9 \mathrm{~mL}$, compared with $27.0 \mathrm{~min}$ and $6.2 \mathrm{~mL}$ in cases who received stereotactic biopsy $(P<0.001$ and $P<0.001)$. The most common complication in both groups was postoperative hemorrhage $(7.0 \%$ and $8.5 \%)$. Patients who received biopsy had higher KPS scores at hospital discharge than on admission in contrast to open craniotomy $(P=0.047)$. Deterioration of KPS at hospital discharge than on admission was observed in 29 and 1 cases who received craniotomy and biopsy $(P<0.001)$.

\section{Conclusions}

Endocrinological alteration has longer duration before diagnosis. Patients with multiple lesions such as bifocal and multifocal germinomas have a higher tendency of dissemination, and additional attention should be paid to the imaging findings. Patients may not necessarily benefit from the surgical resection because of the surgical trauma and the postoperative complications, and stereotactic biopsy is highly significant in clinical practice.

\section{Introduction}

Intracranial germ cell tumors (IGCTs) are a heterogeneous group of tumors with peculiar characteristics, which can be clearly distinguished from other brain tumors of neuroepithelial origin [1]. IGCTs are classified into mature teratoma, immature teratoma, teratoma with somatic-type malignancy, germinoma, embryonal carcinoma, yolk sac tumor, choriocarcinoma, and mixed germ cell tumors according to the 2021 World Health Organization (WHO) Classification of Tumors of the Central Nervous System (CNS) [2]. Besides, germinoma includes pure germinoma and germinoma with syncytiotrophoblastic giant cells (STGCs), accounting for approximately two-thirds of all histological categories. Diagnosis of IGCTs is based on clinical symptoms, tumor markers, histology and imaging findings. Detection of tumor markers (especially beta-human chorionic gonadotropin ( $\beta-\mathrm{HCG})$ and alpha-fetoprotein (AFP)) plays an important role in the diagnosis of IGCTs. Based on the levels of $\beta$-HCG and AFP, IGCTs can be classified into "secreting type" or "non-secreting type"[3], and patients with the former type mainly have a worse prognosis than the latter type because of the presence of the specific malignant components[4]. In clinical practice, elevated levels of tumor markers can help with decision-making for a diagnosis directly in "secreting type", and tumor markers may also be used for monitoring of treatment of patients when in an imaging study it is difficult to assess response to chemotherapy. Regarding cases without elevated levels of tumor markers, biopsy is strongly recommended $[4,5]$. However, there is currently no standard procedure for tissue biopsy. Surgical approaches include stereotactic biopsy, endoscopic biopsy, and open craniotomy, while tissue sampling modalities vary among different regions. In some countries, diagnostic methods still rely on gross total resection rather than on biopsy[4]. 
In the present study, we collected data of patients with histology-proven germinomas, and analyzed their neurological characteristics, treatment procedures, and clinical outcomes.

\section{Patients And Methods Patients}

Data of 232 patients with suspected IGCTs, who were admitted to Sanbo Brain Hospital Capital Medical University (Beijing, China) from January 2012 to June 2021, were retrospectively analyzed. All the diagnoses had been confirmed by the histopathologic examination of the samples collected after stereotactic biopsy $(n=117,50.4 \%)$ and craniotomy $(n=115,49.6 \%)$. As shown in Figure 1 , patients who had received chemotherapy/radiotherapy, surgical resection, gamma knife surgery, or had a history of other malignancies were excluded. Besides, cases with recurrent disease or extracranial metastases, absence of data related to preoperative tumor markers, and non-germinomatous germ cell tumors were ruled out. Based on histological results, the patients were divided into two groups: pure germinoma and germinoma with STGCs.

\section{Data collection}

Patients' clinical data, such as age, gender, clinical manifestations, radiological findings (e.g., computed tomography (CT) and magnetic resonance imaging (MRI) findings), tumor location, histological type, and serum levels of tumor markers were collected from electronic health records. Perioperative data included tissue sampling procedure, extent of resection, operation time, intraoperative blood loss, length of hospital stay, inpatient expenses, pre-operative Karnofsky performance scale (KPS) scores and KPS scores at hospital discharge, and postoperative complications (e.g., hemorrhage, infections, cerebral infarction, new-onset seizure, and subdural and epidural effusion). Preoperative KPS scores were measured on admission. Patients with lesions in basal ganglia were allocated into basal ganglia group. Bifocal diseases were defined as tumors that were located in the pineal and sellar/suprasellar regions synchronously. Multifocal diseases were defined as primary masses presented at $\geq 2$ sites.

\section{Tumor markers}

The serum levels of tumor markers, including AFP and $\beta-H C G$, were measured before tissue sampling. The normal ranges of serum levels of tumor markers ( $\beta-\mathrm{HCG}$ and AFP) were 0-5.0 IU/L and 0-7 ng/ml, respectively.

The criteria for identifying the "non-secreting type" were defined as $\beta-H C G<50 \mathrm{IU} / \mathrm{L}$ and AFP $<25 \mathrm{ng} / \mathrm{ml}$, according to the SIOP guideline [3] and previous studies [6, 7].

\section{Statistical analysis}

Descriptive statistics were used to analyze patients' demographic characteristics at baseline. Categorical variables were compared between groups using the Chi-square test or the Fisher's exact test, as appropriate. Continuous variables were compared using the Student's t-test. The Mann-Whitney $\mathrm{U}$ test and the Kruskal-Wallis $\mathrm{H}$ test were utilized to compare non-parametric values. The statistical analysis was conducted using the SPSS 26.0 software (IBM Corp., Armonk, NY, USA). P $\leq 0.05$ was considered statistically significant.

The study was approved by the Ethics Committee of Sanbo Brain Hospital Affiliated to Capital Medical University (Beijing China).

\section{Results}

\section{Patients' demographic characteristics}

Comparison of patients' demographic characteristics at baseline is outlined in Table 1. Among all 232 cases, there were 162 (69.8\%) men and 70 (30.2\%) women, and male-to-female ratio was 2.3:1. Patients who were diagnosed with pure germinoma and germinoma with STGCs accounted for $88.4 \%(n=205)$ and $11.6 \%(n=27)$ of total number of cases, respectively. The majority of patients aged under 20 years old (range, 0-19 years old; $n=181,78.0 \%$; Figure $2 A$ ). Patients' mean age in the groups of pure germinoma and germinoma with STGCs was $15.3 \pm 6.2$ and $16.9 \pm 6.1$ (range, 4-44 and 6-27) years old, respectively $(P=0.195)$. Patients with basal ganglia lesions (median age, $10.5 \pm 3.0$ years old) experienced a younger age of disease onset than other patients (Figure 2B). 
Table 1

Comparison of characteristics of 232 patients at baseline between pure germinoma and germinoma with STGCs groups.

\begin{tabular}{|c|c|c|c|c|c|c|c|}
\hline & \multirow{2}{*}{\multicolumn{2}{|c|}{$\begin{array}{l}\text { Total } \\
n=232\end{array}$}} & \multicolumn{2}{|c|}{ Pure Germinoma } & \multicolumn{2}{|c|}{ Germinoma with STGCs } & \multirow[t]{2}{*}{$P$} \\
\hline & & & \multicolumn{2}{|c|}{$\mathrm{n}=\mathbf{2 0 5}$} & \multicolumn{2}{|c|}{$\mathrm{n}=27$} & \\
\hline \multicolumn{7}{|l|}{ Age, years old } & 0.195 \\
\hline Mean \pm standard deviation & \multicolumn{2}{|c|}{$15.5 \pm 6.2$} & \multicolumn{2}{|c|}{$15.3 \pm 6.2$} & \multicolumn{2}{|c|}{$16.9 \pm 6.1$} & \\
\hline Median & \multicolumn{2}{|l|}{14} & \multicolumn{2}{|l|}{14} & \multicolumn{2}{|l|}{15} & \\
\hline Range & \multicolumn{2}{|l|}{$4-44$} & \multicolumn{2}{|l|}{$4-44$} & \multicolumn{2}{|c|}{$6-27$} & \\
\hline \multicolumn{7}{|l|}{ Gender, n \% } & 0.465 \\
\hline Male & 162 & $69.8 \%$ & 145 & $70.7 \%$ & 17 & $63.0 \%$ & \\
\hline Female & 70 & $30.2 \%$ & 60 & $29.3 \%$ & 10 & $37.0 \%$ & \\
\hline \multicolumn{7}{|l|}{ Tumor location, n \% } & 0.222 \\
\hline Sellar/suprasellar region & 77 & $33.2 \%$ & 69 & $33.7 \%$ & 8 & $29.6 \%$ & \\
\hline Pineal region & 58 & $25.0 \%$ & 53 & $25.9 \%$ & 5 & $18.5 \%$ & \\
\hline Basal ganglia & 35 & $15.1 \%$ & 28 & $13.7 \%$ & 7 & $25.9 \%$ & \\
\hline Bifocal region & 33 & $14.2 \%$ & 31 & $15.1 \%$ & 2 & $7.4 \%$ & \\
\hline Multifocal region & 23 & $9.9 \%$ & 20 & $9.8 \%$ & 3 & $11.2 \%$ & \\
\hline Other regions & 6 & $2.6 \%$ & 4 & $1.8 \%$ & 2 & $7.4 \%$ & \\
\hline \multicolumn{8}{|l|}{ Imaging findings } \\
\hline Hydrocephalus & 88 & $37.9 \%$ & 79 & $38.5 \%$ & 9 & $33.3 \%$ & 0.600 \\
\hline Intracranial dissemination & 61 & $26.3 \%$ & 51 & $24.9 \%$ & 10 & $37.0 \%$ & 0.177 \\
\hline
\end{tabular}

In the pure germinoma group, tumors were located in sellar/suprasellar region in 69 (33.7\%), in pineal region in 53 (25.9\%), in basal ganglia in 28 (13.7\%), in bifocal region in 31 (15.1\%), in multifocal region in 20 (9.8\%), and in other regions in 4 (1.8\%) cases. In the germinoma with STGCs group, tumors were located in sellar/suprasellar region in 8 (29.6\%), in pineal region in 5 (18.5\%), in basal ganglia in 7 (25.9\%), in bifocal region in 2 (7.4\%), in multifocal region in $3(11.2 \%)$, and in other regions in 2 (7.4\%) cases. No significant difference was found in tumor location between the two groups $(P=0.222)$.

In addition, female patients with lesions located in the sellar/suprasellar region accounted for 74.3\% ( $\mathrm{n=52}$ ) (Figure 2C). The male-tofemale ratio in the sellar/suprasellar region was 1:2.1, 57:1 in the pineal region, 7.8:1 in basal ganglia, 4.5:1 in bifocal region, and 2.3:1 in multifocal region.

\section{Clinical presentations}

Polyuria and/or polydipsia was the most common symptom ( $n=99,42.7 \%)$, followed by headache ( $n=94,40.5 \%)$, visual disturbance $(n=87,37.5 \%)$, motor impairment $(n=66,28.4 \%)$, nausea/vomiting $(n=57,24.6 \%)$, and dizziness/vertigo ( $n=40,17.2 \%)$. Several patients presented with menstruation disorders $(n=19)$, growth retardation $(n=15)$, hearing impairment $(n=10)$, slurred speech $(n=7)$, memory defection $(n=6)$, incontinence $(n=5)$, and precocious puberty $(n=2)$.

Patients with ophthalmologic abnormalities accounted for $37.5 \%$ of all patients and presented with blurred vision, visual field defects, diplopia, ptosis, and strabismus. More than half of the patients $(40 / 66,60.6 \%)$ with tumors at basal ganglia suffered from motor impairment. The common symptoms included limb weakness, limb numbness, limb trembling, ataxia, abnormal muscle tone, and fine motor skills. 
Polyuria/polydipsia was predominantly observed in patients with tumors located in sellar/suprasellar region (60/77, $77.9 \%)$ and bifocal region $(24 / 33,72.7 \%)$. Headache and nausea/vomiting are the symptoms of increased intracranial pressure and are strongly correlated to hydrocephalus ( $P<0.001$ and $P<0.001$, respectively). The majority of patients ( 32 of $35,91.4 \%$ ) with tumors in basal ganglia suffered from motor impairment. In multifocal region, 12 cases experienced motor impairment, of whom 8 (66.7\%) cases had tumors in the basal ganglia.Besides, 6 of 162 (3.7\%) male patients had growth retardation and 9 of $70(12.9 \%)$ were women $(P=0.017)$. Moreover, $12(80.0 \%)$ patients with growth retardation were identified before puberty (age, $\leq 14$ years old), and the preference of patients before puberty presented with growth retardation was observed $(P=0.043)$. Menstruation disorders, such as irregular menstruation and amenorrhea, were observed in 19 cases, which were related to the sellar/suprasellar region $(n=15)$, bifocal region $(n=2)$, and multifocal region $(n=2))$. Two patients had precocious puberty and they all were male with tumors located in the basal ganglia. The elevation of serum $\beta$-HCG level was observed in all patients (21.39 IU/L and $21.63 \mathrm{IU} / \mathrm{L})$.

The duration of symptoms before hospital admission was outlined in Table 2. Comparing with other symptoms, the symptoms of endocrinological alteration had significant longer duration.

Table 2

Clinical presentations and the duration of symptoms of 232 patients with germinomas.

\begin{tabular}{|lllllll}
\hline & \multicolumn{2}{l}{ Total } & \multicolumn{2}{l}{ Within 6 Months } & \multicolumn{2}{l}{ More Than 6 Months } \\
\cline { 2 - 7 } & $\mathbf{n}$ & $\%$ & $\mathbf{n}$ & $\%$ & $\mathbf{n}$ & $\%$ \\
\hline Neurological presentations & & & & & & \\
\hline Headache & 94 & $40.5 \%$ & 77 & $81.9 \%$ & 17 & $18.1 \%$ \\
\hline Nausea/Vomiting & 57 & $24.6 \%$ & 45 & $78.9 \%$ & 12 & $21.1 \%$ \\
\hline Dizziness/Vertigo & 40 & $17.2 \%$ & 29 & $72.5 \%$ & 11 & $27.5 \%$ \\
\hline Neurological function impairment & & & & & & \\
\hline Visual disturbances & 87 & $37.5 \%$ & 72 & $80.5 \%$ & 15 & $19.5 \%$ \\
\hline Motor impairment & 66 & $28.4 \%$ & 44 & $66.7 \%$ & 22 & $33.3 \%$ \\
\hline Hearing impairment & 10 & $4.3 \%$ & 10 & $100 \%$ & 0 & $0 \%$ \\
\hline Incontinence & 5 & $2.2 \%$ & 4 & $80.0 \%$ & 1 & $20.0 \%$ \\
\hline Endocrinological Alternation & & & & & & \\
\hline Polyuria/Polydipsia & 99 & $42.7 \%$ & 14 & $14.1 \%$ & 85 & $85.9 \%$ \\
\hline Menstruation disorders & 19 & $8.2 \%$ & 3 & $15.8 \%$ & 16 & $84.2 \%$ \\
\hline Growth retardation & 15 & $6.5 \%$ & 0 & $0 \%$ & 15 & $100 \%$ \\
\hline Precocious puberty & 2 & $0.9 \%$ & 0 & $0 \%$ & 2 & $100 \%$ \\
\hline Neurocognitive Disorders & & & & & & \\
\hline Slurred speech & 7 & $3.0 \%$ & 4 & $57.1 \%$ & 3 & $42.9 \%$ \\
\hline Memory defection & 6 & $2.6 \%$ & 5 & $83.3 \%$ & 1 & $16.7 \%$ \\
\hline Within 6 months: the duration $<6$ months; More than 6 months: the duration $\geq 6$ months. & \\
\hline
\end{tabular}

\section{Tumor markers}

Among the 232 cases, a mild elevation of serum $\beta$-HCG level (>5.0 IU/L) was found in 9 of $27(33.3 \%)$ patients in the germinoma with STGCs group and 28 of $205(13.7 \%)$ in the pure germinoma group. As illustrated in Figure 3A, the median serum level of $\beta$-HCG was 
$2.50 \mathrm{IU} / \mathrm{L}$ and $0.86 \mathrm{IU} / \mathrm{L}$ in the two groups, respectively. There was a statistically significant difference between the two groups $(P=0.001)$.

Of the 5 cases with an elevated serum level of AFP $(>7 \mathrm{ng} / \mathrm{ml}), 1$ case in the germinoma with STGCs group and 4 cases in the pure germinoma group were detected. Figure 3B shows the profile of the serum AFP level in two groups. The median serum level of AFP was $2.71 \mathrm{ng} / \mathrm{ml}$ and $2.28 \mathrm{ng} / \mathrm{ml}$ in the two groups, respectively, and no significant difference was noted between the two groups $(P=0.540)$.

\section{Intracranial dissemination and spinal seeding}

Cranial imaging data of all patients were assessed, in which 61 (26.3\%) patients had intracranial dissemination, including intracranial ventricular seeding and extraventricular seeding, 10 and 51 patients were diagnosed with germinoma with STGCs and pure germinoma, respectively. No statistically significant difference was identified between the two groups $(P=0.177)$. Tumors' locations were strongly associated with intracranial dissemination $(P<0.001)$, in which tumors that were located in bifocal or multifocal regions were easily spread $(21 / 33,63.6 \%$ and $13 / 23,56.5 \%$, respectively) compared with tumors in the sellar/suprasellar region $(10 / 77,13.0 \%)$, pineal region $(14 / 58,24.1 \%)$, and tumors in basal ganglia showed a significant reluctance to cerebrospinal fluid (CSF) dissemination (2/35, 5.7\%). Furthermore, when patients with primary tumors located in the sellar/suprasellar region, pineal region, basal ganglia, and other regions were assigned to the group of solitary lesion, the difference in intracranial dissemination among different locations was statistically significant compared with tumors presenting with multiple lesions in bifocal of multifocal diseases( $15.3 \%$ vs. $60.7 \%, P<0.001)$.

Among 121 cases with available spinal MRI data, 30 (24.8\%) cases had spinal seeding (Table 3 ), in which 2 and 28 cases were in germinoma with STGCs and pure germinoma groups, respectively $(P=0.514)$. In patients with tumors located at sellar/suprasellar region, 6 of $36(16.7 \%)$ had spinal seeding, and 4 of $29(13.8 \%)$ and 3 of $19(15.8 \%)$ had tumors in in the pineal region and basal ganglia, respectively. In contrast, 13 of 21 (61.9\%) cases had tumors located in bifocal region and 4 of 12 (33.3\%) had tumors located in multifocal region, which indicated spinal seeding. There was a noticeable association for sites according to spinal MRI findings $(P=0.002)$. When localized cases were compared with those with bifocal or multifocal lesions, the trend of spinal seeding appeared statistically significant $(14.8 \%$ vs. $51.5 \%, P<0.001)$.

Table 3

Details of spinal seeding of 121 patients with available MRI

results.

\begin{tabular}{|c|c|c|c|c|c|}
\hline & \multicolumn{4}{|c|}{ Spinal Seeding } & \multirow[t]{3}{*}{$P$} \\
\hline & \multicolumn{2}{|c|}{ Yes } & \multicolumn{2}{|l|}{ No } & \\
\hline & $\mathrm{n}$ & $\%$ & $\mathbf{n}$ & $\%$ & \\
\hline \multicolumn{6}{|l|}{ Locations } \\
\hline Sellar/Suprasellar & 6 & 16.7 & 30 & 83.3 & \multirow[t]{6}{*}{$0.002^{*}$} \\
\hline Pineal & 4 & 13.8 & 25 & 86.2 & \\
\hline Basal Ganglia & 3 & 15.8 & 16 & 84.2 & \\
\hline Bifocal & 13 & 61.9 & 8 & 38.1 & \\
\hline Multifocal & 4 & 33.3 & 8 & 66.7 & \\
\hline Other & 0 & 0 & 4 & 100 & \\
\hline \multicolumn{6}{|l|}{ Types of Diseases } \\
\hline Solitary Lesion & 13 & 14.8 & 75 & 85.2 & \multirow[t]{2}{*}{$<0.001^{*}$} \\
\hline Multiple Lesions & 17 & 51.5 & 16 & 48.5 & \\
\hline$* P<0.05$ & & & & & \\
\hline
\end{tabular}

Page 6/16 


\section{Clinical outcomes}

A total of 115 patients underwent craniotomy and 117 patients received stereotactic biopsy. The mean operation time of open craniotomy was $268.8 \mathrm{~min}$ with an average volume of blood loss of $316.9 \mathrm{ml}$, compared with $27.0 \mathrm{~min}$ and $6.2 \mathrm{ml}$ for stereotactic biopsy ( $P<0.001$ and $P<0.001$, respectively; Table 4). Significant differences were also observed in length of hospital stay and inpatient expenses between these two surgical approaches ( $P<0.001$ and $P<0.001$, respectively). As shown in Table 4, a total of 66 patients developed postoperative complications and the most common complication was postoperative hemorrhage. Other complications included postoperative effusion ( $n=16,6.9 \%)$, infections $(n=14,6.0 \%)$, new-onset seizure $(n=7,3.0 \%)$, postoperative hydrocephalus $(n=7,3.0 \%)$, and cerebral infarction $(n=2,0.9 \%)$. Moreover, the perioperative mortality was $0.4 \%$. One patient died on the 8th day after receiving gross total resection because of suspected pulmonary embolism. 
Table 4

Perioperative data, postoperative complications and Karnofsky performance scale (KPS) scores of 232 patients with germinomas.

\begin{tabular}{|c|c|c|c|c|c|c|c|}
\hline \multirow{3}{*}{$\begin{array}{l} \\
\text { Postoperative } \\
\text { Complications }\end{array}$} & \multirow{2}{*}{\multicolumn{2}{|c|}{$\begin{array}{l}\text { All } \\
\mathbf{n}=232\end{array}$}} & \multirow{2}{*}{\multicolumn{2}{|c|}{$\begin{array}{l}\text { Craniotomy } \\
\mathrm{n}=115\end{array}$}} & \multirow{2}{*}{\multicolumn{2}{|c|}{$\begin{array}{l}\text { Biopsy } \\
\mathbf{n = 1 1 7}\end{array}$}} & \multirow[t]{3}{*}{$\mathrm{P}$} \\
\hline & & & & & & & \\
\hline & $\mathbf{n}$ & $\%$ & $n$ & $\%$ & $n$ & $\%$ & \\
\hline $\begin{array}{l}\text { Postoperative } \\
\text { hemorrhage }\end{array}$ & 18 & 7.8 & 8 & 7 & 10 & 8.5 & 0.651 \\
\hline $\begin{array}{l}\text { Intracerebral } \\
\text { hemorrhage }\end{array}$ & 12 & 5.2 & 5 & 4.3 & 7 & 6 & 0.574 \\
\hline $\begin{array}{l}\text { Subdural } \\
\text { hemorrhage }\end{array}$ & 3 & 1.3 & 3 & 2.6 & 0 & 0 & 0.12 \\
\hline $\begin{array}{l}\text { Epidural } \\
\text { hemorrhage }\end{array}$ & 5 & 2.2 & 1 & 0.9 & 4 & 3.4 & 0.37 \\
\hline $\begin{array}{l}\text { Postoperative } \\
\text { effusion }\end{array}$ & 16 & 6.9 & 16 & 13.9 & 0 & 0 & $<0.001 *$ \\
\hline $\begin{array}{l}\text { Subdural } \\
\text { effusion }\end{array}$ & 10 & 4.3 & 10 & 8.7 & 0 & 0 & $0.001 *$ \\
\hline $\begin{array}{l}\text { Epidural } \\
\text { effusion }\end{array}$ & 5 & 2.2 & 5 & 4.3 & 0 & 0 & $0.029 *$ \\
\hline $\begin{array}{l}\text { Subcutaneous } \\
\text { effusion }\end{array}$ & 5 & 2.2 & 5 & 4.3 & 0 & 0 & $0.029 *$ \\
\hline $\begin{array}{l}\text { Postoperative } \\
\text { infections }\end{array}$ & 14 & 6 & 14 & 12.2 & 0 & 0 & $<0.001 *$ \\
\hline $\begin{array}{l}\text { Intracranial } \\
\text { infection }\end{array}$ & 10 & 4.3 & 10 & 8.7 & 0 & 0 & $0.001 *$ \\
\hline $\begin{array}{l}\text { Scalp incision } \\
\text { infection }\end{array}$ & 0 & 0 & 0 & 0 & 0 & 0 & NA \\
\hline $\begin{array}{l}\text { Pulmonary } \\
\text { infection }\end{array}$ & 4 & 1.7 & 4 & 3.5 & 0 & 0 & 0.059 \\
\hline $\begin{array}{l}\text { New-onset } \\
\text { seizures }\end{array}$ & 7 & 3 & 7 & 6.1 & 0 & 0 & $0.007 *$ \\
\hline $\begin{array}{l}\text { Postoperative } \\
\text { hydrocephalus }\end{array}$ & 7 & 3 & 6 & 5.2 & 1 & 0.9 & 0.065 \\
\hline $\begin{array}{l}\text { Postoperative } \\
\text { cerebral } \\
\text { infarction }\end{array}$ & 2 & 0.9 & 2 & 1.7 & 0 & 0 & 0.245 \\
\hline $\begin{array}{l}\text { Perioperative } \\
\text { data }\end{array}$ & MeanıSD & $\begin{array}{l}\text { Median } \\
\text { (range) }\end{array}$ & MeanıSD & $\begin{array}{l}\text { Median } \\
\text { (range) }\end{array}$ & Mean士SD & $\begin{array}{l}\text { Median } \\
\text { (range) }\end{array}$ & \\
\hline $\begin{array}{l}\text { Operative time } \\
\text { (min) }\end{array}$ & $146.9 \pm 133.6$ & $\begin{array}{l}139.5(10- \\
525)\end{array}$ & $268.8 \pm 73.4$ & $\begin{array}{l}265 \text { (144- } \\
525)\end{array}$ & $27.0 \pm 31.1$ & $\begin{array}{l}20(10- \\
260)\end{array}$ & $<0.001 *$ \\
\hline $\begin{array}{l}\text { Intraoperative } \\
\text { blood loss } \\
\text { (ml) }\end{array}$ & $160.2 \pm 217.8$ & $\begin{array}{l}50(1- \\
1600)\end{array}$ & $316.9 \pm 216.6$ & $\begin{array}{l}300(50- \\
1600)\end{array}$ & $6.2 \pm 11.5$ & $1(1-100)$ & $<0.001 *$ \\
\hline $\begin{array}{l}\text { Length of } \\
\text { hospital stay } \\
\text { (days) }\end{array}$ & $16.5 \pm 8.4$ & $\begin{array}{l}14.5(5- \\
48)\end{array}$ & $22.0 \pm 8.1$ & $21(9-48)$ & $11.1 \pm 4.1$ & $10(5-28)$ & $<0.001 *$ \\
\hline
\end{tabular}




\begin{tabular}{|c|c|c|c|c|c|c|c|}
\hline $\begin{array}{l}\text { Inpatient } \\
\text { expenses (\#) }\end{array}$ & $67906.2 \pm 37997.4$ & $\begin{array}{l}61777.1 \\
(10222.1- \\
279012.7)\end{array}$ & $95047.1 \pm 34607.2$ & $\begin{array}{l}89341.0 \\
(10222.1- \\
279012.7)\end{array}$ & $41229 \pm 15813.6$ & $\begin{array}{l}36766.5 \\
(22333.9- \\
104506.9)\end{array}$ & $<0.001 *$ \\
\hline $\begin{array}{l}\text { Karnofsky } \\
\text { performance } \\
\text { scale (KPS) } \\
\text { scores }\end{array}$ & Mean & $\begin{array}{l}\text { Median } \\
\text { (range) }\end{array}$ & Mean & $\begin{array}{l}\text { Median } \\
\text { (range) }\end{array}$ & Mean & $\begin{array}{l}\text { Median } \\
\text { (range) }\end{array}$ & \\
\hline $\begin{array}{l}\text { Preoperative } \\
\text { KPS }\end{array}$ & 86.1 & $\begin{array}{l}90(50- \\
100)\end{array}$ & 85.2 & $\begin{array}{l}90(70- \\
100)\end{array}$ & 88.8 & $\begin{array}{l}90(60- \\
100)\end{array}$ & $<0.001 *$ \\
\hline $\begin{array}{l}\text { KPS at } \\
\text { hospital } \\
\text { discharge }\end{array}$ & 85.7 & $90(0-100)$ & 81.0 & $80(0-90)$ & 89.7 & $\begin{array}{l}90(60- \\
100)\end{array}$ & $<0.001 *$ \\
\hline $\begin{array}{l}\text { Discharge-pre } \\
\triangle \text { KPS }\end{array}$ & -0.4 & & -1.7 & & 0.9 & & $0.047^{*}$ \\
\hline $\begin{array}{l}\text { Deterioration } \\
\text { of KPS at } \\
\text { discharge No. } \\
(\%)\end{array}$ & $30(12.9)$ & & $29(25.2)$ & & $1(0.9)$ & & $<0.001 *$ \\
\hline$* P<0.05$ & & & & & & & \\
\hline
\end{tabular}

The KPS scores are summarized in Table 4. As displayed in Figure 4,patients who received biopsy had higher KPS scores at hospital discharge than on admission in contrast to open craniotomy $(P=0.047)$. Besides, stereotactic biopsy showed a lower reduction of KPS scores at hospital discharge (0.9) compared with craniotomy (-1.7).

Deterioration of KPS at hospital discharge compared with on admission was observed in 30 patients, of whom 29 and 1 patients received craniotomy and biopsy, respectively $(P<0.001)$.

\section{Discussion}

Intracranial germinomas are extremely sensitive to chemotherapy and radiotherapy. Accurate diagnosis and differential diagnosis are critical to implement effective therapeutic regimens, especially in cases without noticeable elevation of the serum levels of tumor markers. We conducted the present retrospective study on a large cohort of patients with "non-secreting" germinomas, reported patients' characteristics at baseline, performed treatment procedures, and analyzed the clinical short-term outcomes.

The present study revealed that there were no statistically significant differences in age, gender, and tumor location between germinoma with STGCs and pure germinoma groups. Besides, germinomas at pineal region mainly occurred in men, while germinomas at sellar/suprasellar region showed a higher frequency in female patients. The preference of gender in different regions might illustrate that the biological behavior of germinomas in different locations might vary because of the potential mechanisms. Patients with basal ganglia germinomas were younger than those with tumors at sellar/suprasellar and pineal regions. These results could be associated with patients' clinical symptoms. Patients with basal ganglia germinomas are always accompanied with motor impairment, and the symptoms could be detected at the early-stage of onset. However, delay in diagnosis mainly occurs in patients with sellar/suprasellar germinomas because of the discernible presentations and the negative imaging results during the early-stage [8-10]. This is similar with our results of duration of the symptoms. Endocrinological alteration had significant longer duration, some symptoms like polyuria/polydipsia, growth retardation and menstruation disorders may persist for years before diagnosis. With the slow growth of tumors, patients with pineal lesions may have manifestations in the advanced-stage.

Intracranial germ cell tumors have a trend to disseminate throughout the neuroaxis of the ventricles and spinal subarachnoidal space $[11,12]$. In the present study, intracranial dissemination was detected in 61 (26.3\%) patients, and a statistically significant difference was found in distribution of primary tumor locations $(P<0.001)$. Intracranial tumor seeding was significantly associated with bifocal and multifocal regions, whereas tumors from the basal ganglia region showed a remarkable reluctance to CSF dissemination. The higher rate of ventricular seeding in bifocal tumors was previously reported, in which $47.8 \%$ of patients with bifocal tumors presented with tumor seeding in comparison with $11.4 \%$ without bifocal tumors [13]. Besides, $24.8 \%$ of patients who 
received MRI of spine had spinal seeding in the present research. The spinal seeding rate of cases with bifocal or multifocal lesions was higher than that in the other regions. The rate of spinal seeding in pathologically proved intracranial germinoma was reported to be in the range of $5-13 \%$ [14], which was lower than that in our study.

Whether the bifocal germinoma is a synchronous local disease or disseminated disease remains controversial. Previous studies reported that no recurrence after therapy was found in patients with bifocal tumors who only received ventricular radiotherapy without spinal irradiation, indicating that bifocal germinoma was a localized disease $[15,16]$. However, other scholars demonstrated that patients with bifocal germinoma who were treated with craniospinal irradiation presented with no treatment failure, while recurrence was observed in cases who were treated without spinal irradiation, suggesting that bifocal germinoma would be a disseminated disease [17-20]. Based on the significant trend of dissemination and the results of our study, we hypothesized that bifocal tumors may result from the metastatic spread of suprasellar or pineal tumors rather than synchronous oligometastatic disease. Meanwhile, intracranial dissemination and spinal seeding are important factors influencing the therapeutic outcomes, and further aggressive treatments are therefore required $[13,21]$. We suggest that neurosurgeons should pay additional attention to the imaging findings at diagnosis, especially in bifocal and multifocal diseases, to assess the patients' status comprehensively.

In our study, we observed that the preoperative KPS scores significantly differed between the two groups, and it was found that a worse clinical status on admission could be related to hydrocephalus. In patients presented with hydrocephalus, lower KPS scores were identified in the open craniotomy group compared with those in the biopsy group ( $81.4 \pm 13.3 \mathrm{vs}$. $88.8 \pm 7.8, P=0.009)$. No significant difference in KPS scores was detected between the two groups $(85.2 \pm 9.3$ vs. $88.8 \pm 9.5, P=0.624)$. Patients who underwent open craniotomy had lower KPS scores than those who underwent biopsy and the deterioration of KPS scores at discharge was observed in 29 of 115 cases, which indicated that some patients might not benefit from the surgical resection because of the surgical trauma and the postoperative complications. SAWAMURA et al. found that radical resection of intracranial germinomas was not advantageous compared with biopsy, and they suggested that when the histological diagnosis of pure germinoma is made by craniotomy, no risk should be taken to pursue extended resection [22]. In another research, no significant difference in 5-year eventfree survival or progression-free survival was noted between patients with residual lesions and those without residual lesions [3]. Thus, according to the lower decrease of KPS scores at discharge in the biopsy group, extended resection may not be necessary when diagnosis was confirmed by intraoperative tissue biopsy during craniotomy.

Importantly, biopsy is less traumatic than open craniotomy in patients with a shorter length of hospital stay. However, postoperative complications should not be ignored, especially postoperative hemorrhage. In our study, intracerebral hemorrhage and epidural hemorrhage after biopsy were found in 7 (6.0\%) and 4 (3.4\%) cases, respectively. All cases presented with a small amount of hemorrhage and required no surgical intervention except for one case. In a 14-year-old male patient, epidural hemorrhage after stereotactic biopsy was noted that accompanied with the gradually increase of the amount of hemorrhage, and the volume of hemorrhage on CT was $64 * 22 \mathrm{~mm}$, in which the patient subsequently received craniotomy for evacuation of the hematoma. Postoperative hemorrhage is the most common complication of stereotactic biopsy, with an incidence of 4.7\%-9.0\%[23-26]. With the development of the stereotactic biopsy planning software merged with imaging examinations (e.g., CT and MRI), it is important for neurosurgeons to provide accurate and safe biopsies to prevent cerebral hemorrhage. Barkley et al. reported that immediate and delayed postoperative deficits and seizures were highly correlated to post-biopsy hemorrhage, and they recommended the use of postoperative CT as a screening tool to evaluate a patient's clinical status after biopsy [27], which was consistent with the objectives of our research. Thus, cranial CT as a routine examination after biopsy is recommended to avoid hemorrhage-associated adverse events.

The limitations of this study should be pointed out. First, as a retrospective and observational study, selection bias and recall bias were inevitable. All of our cases were selected depending on the histological diagnosis. Second, biopsy might be not valuable for patients with intermediate serum levels of tumor markers, and such patients might alternatively receive chemoradiotherapy. Third, within half of the cases underwent stereotactic biopsy, and specimens might not fully reflect the characteristics of tumors and increase the possibility of under-diagnosis. However, multi-target biopsy may increase the accuracy of the results. Fourth, there were missing data because of unstandardized patterns of diagnosis, A considerable proportion of cases had no data of the levels of CSF tumor markers, besides, the lack of spinal MRI results and cytological examination results of CSF might negatively influence the reliability of our findings. 
The treatment strategies of intracranial germ cell tumors still rely on chemoradiotherapy, the further study should combine the details of the follow-up treatment after accurate diagnosis in order to demonstrate the effect of tumor removal and point out the influences to the prognosis and recurrence.

\section{Conclusions}

Endocrinological alteration has longer duration before diagnosis. Intracranial dissemination and spinal seeding are significantly correlated to tumor locations, and patients with multiple lesions such as bifocal and multifocal germinomas have a higher tendency of dissemination. Additional attention should be paid to the imaging findings in clinical practice, especially in bifocal and multifocal diseases. Patients may not necessarily benefit from surgical resection because of the surgical trauma and the postoperative complications, and stereotactic biopsy is highly advantageous and is recommended.

\section{Declarations}

\section{Conflicts of interest:}

All authors have no competing interest (eg. Employment, consultancies honoraria, stock ownership or option, grants, contracts, patents received or royalties) to declare.

January.21, 2022

\section{Availability of data and materialn}

All data generated or analysed during this study are included in this published article.

\section{Code availability[}

No available code in the manuscript.

\section{Ethics approval $\square$}

The study was approved by the Ethics Committee of Sanbo Brain Hospital Affiliated to Capital Medical University (Beijing China).

\section{Consent to participate[}

We confirm that the manuscript has been read and approved by all named authors. We further confirm that the order of authors listed in the manuscript has been approved by all of us.

\section{Authors' contributions}

Jiajun Zhou, MB: Formal analysis, Investigation, Data curation, Writing - Original Draft, Visualization

Ting Lei, MD: Conceptualization, Methodology, Writing - Review \& Editing

Jinyi Zuo, MB: Investigation, Data curation

Chenxing Wu, MD: Validation, Writing - Review \& Editing

Rui Liu, MD: Validation, Writing - Review \& Editing

Shouwei Li, MD『Conceptualization, Methodology, Writing - Review \& Editing, Project administration

\section{References}

1. McCarthy BJ, Shibui S, Kayama T, Miyaoka E, Narita Y, Murakami M, Matsuda A, Matsuda T, Sobue T, Palis BE, Dolecek TA, Kruchko C, Engelhard HH, Villano JL (2012) Primary CNS germ cell tumors in Japan and the United States: an analysis of 4 tumor registries. Neuro Oncol 14:1194-1200. https://doi.org/10.1093/neuonc/nos155 
2. Louis DN, Perry A, Wesseling P, Brat DJ, Cree IA, Figarella-Branger D, Hawkins C, Ng HK, Pfister SM, Reifenberger G, Soffietti R, von Deimling A, Ellison DW (2021) The 2021 WHO Classification of Tumors of the Central Nervous System: a summary. Neuro Oncol 23:1231-1251. https://doi.org/10.1093/neuonc/noab106

3. Calaminus G, Kortmann R, Worch J, Nicholson JC, Alapetite C, Garre ML, Patte C, Ricardi U, Saran F, Frappaz D (2013) SIOP CNS GCT 96: final report of outcome of a prospective, multinational nonrandomized trial for children and adults with intracranial germinoma, comparing craniospinal irradiation alone with chemotherapy followed by focal primary site irradiation for patients with localized disease. Neuro Oncol 15:788-796. https://doi.org/10.1093/neuonc/not019

4. Murray MJ, Bartels U, Nishikawa R, Fangusaro J, Matsutani M, Nicholson JC (2015) Consensus on the management of intracranial germ-cell tumours. Lancet Oncol 16:e470-e477. https://doi.org/10.1016/s1470-2045(15)00244-2

5. Kong Z, Wang Y, Dai C, Yao Y, Ma W, Wang Y (2018) Central Nervous System Germ Cell Tumors: A Review of the Literature. J Child Neurol 33:610-620. https://doi.org/10.1177/0883073818772470

6. Takami H, Fukuoka K, Fukushima S, Nakamura T, Mukasa A, Saito N, Yanagisawa T, Nakamura H, Sugiyama K, Kanamori M, Tominaga T, Maehara T, Nakada M, Kanemura Y, Asai A, Takeshima H, Hirose Y, luchi T, Nagane M, Yoshimoto K, Matsumura A, Kurozumi K, Nakase H, Sakai K, Tokuyama T, Shibui S, Nakazato Y, Narita Y, Nishikawa R, Matsutani M, Ichimura K (2019) Integrated clinical, histopathological, and molecular data analysis of 190 central nervous system germ cell tumors from the iGCT Consortium. Neuro Oncol 21:1565-1577. https://doi.org/10.1093/neuonc/noz139

7. Calaminus G, Bamberg M, Baranzelli MC, Benoit Y, di Montezemolo LC, Fossati-Bellani F, Jurgens H, Kuhl HJ, Lenard HG, Curto ML et al (1994) Intracranial germ cell tumors: a comprehensive update of the European data. Neuropediatrics 25:26-32. https://doi.org/10.1055/s-2008-1071577

8. Sethi RV, Marino R, Niemierko A, Tarbell NJ, Yock TI, MacDonald SM (2013) Delayed diagnosis in children with intracranial germ cell tumors. J Pediatr 163:1448-1453. https://doi.org/10.1016/j.jpeds.2013.06.024

9. Zhang Y, Deng K, Zhu H, Lu L, Pan H, Ma W, Wang R, Yao Y (2019) Delays in Diagnosis of Pediatric Histologically Confirmed Sellar Germ Cell Tumors in China: A Retrospective Risk Factor Analysis. World Neurosurg 122:e472-e479. https://doi.org/10.1016/j.wneu.2018.10.082

10. Chang HY, Chiu CF, Jung SM, Wong AM, Wu CT, Lo FS (2021) Neurological and endocrinological manifestations of 49 children with intracranial pure germinoma at initial diagnosis in Taiwan. Pediatr Neonatol 62:106-112.

https://doi.org/10.1016/j.pedneo.2020.07.017

11. Dufour C, Guerrini-Rousseau L, Grill J (2014) Central nervous system germ cell tumors: an update. Curr Opin Oncol 26:622-626. https://doi.org/10.1097/CCO.0000000000000140

12. Tosaka M, Ogimi T, Itoh J, Itoh H, Hayashi S, Ono N, Nagaya T (2003) Spinal epidural metastasis from pineal germinoma. Acta Neurochir (Wien) 145:407-410 discussion 410. https://doi.org/10.1007/s00701-003-0022-5

13. Phi JH, Kim SK, Lee J, Park CK, Kim IH, Ahn HS, Shin HY, Kim IO, Jung HW, Kim DG, Paek SH, Wang KC (2013) The enigma of bifocal germ cell tumors in the suprasellar and pineal regions: synchronous lesions or metastasis? J Neurosurg Pediatr 11:107114. https://doi.org/10.3171/2012.10.PEDS11487

14. Brada M, Rajan B (1990) Spinal seeding in cranial germinoma. Br J Cancer 61:339-340. https://doi.org/10.1038/bjc.1990.69

15. Huang PI, Chen YW, Wong TT, Lee YY, Chang KP, Guo WY, Chang FC, Liang ML, Chen HH, Chiou SH, Yen SH (2008) Extended focal radiotherapy of $30 \mathrm{~Gy}$ alone for intracranial synchronous bifocal germinoma: a single institute experience. Childs Nerv Syst 24:1315-1321. https://doi.org/10.1007/s00381-008-0648-y

16. Lafay-Cousin L, Millar BA, Mabbott D, Spiegler B, Drake J, Bartels U, Huang A, Bouffet E (2006) Limited-field radiation for bifocal germinoma. Int J Radiat Oncol Biol Phys 65:486-492. https://doi.org/10.1016/j.ijrobp.2005.12.011

17. Weksberg DC, Shibamoto Y, Paulino AC (2012) Bifocal intracranial germinoma: a retrospective analysis of treatment outcomes in 20 patients and review of the literature. Int J Radiat Oncol Biol Phys 82:1341-1351. https://doi.org/10.1016/j.ijrobp.2011.04.033

18. Zhang Y, Zhu H, Deng K, Ma W, Wang Y, Sun J, Lian X, Pan H, Wang R, Yao Y (2018) Results of Biopsy-Proven Sellar Germ Cell Tumors: Nine Years' Experience in a Single Center. World Neurosurg 112:e229-e239.

https://doi.org/10.1016/j.wneu.2018.01.028

19. Ogawa K, Yoshii Y, Shikama N, Nakamura K, Uno T, Onishi H, Itami J, Shioyama Y, Iraha S, Hyodo A, Toita T, Kakinohana Y, Tamaki W, Ito H, Murayama S (2008) Spinal recurrence from intracranial germinoma: risk factors and treatment outcome for

Page 12/16 
spinal recurrence. Int J Radiat Oncol Biol Phys 72:1347-1354. https://doi.org/10.1016/j.ijrobp.2008.03.055

20. Chung SY, Han JW, Kim DS, Yoon HI, Suh CO (2019) Treatment outcomes based on radiation therapy fields for bifocal germinoma: Synchronous or disseminated disease? PLoS ONE 14:e0223481. https://doi.org/10.1371/journal.pone.0223481

21. Nishizaki T, Kajiwara K, Adachi N, Tsuha M, Nakayama H, Ohshita N, Ikeda N, Ito H, Suzuki M (2001) Detection of craniospinal dissemination of intracranial germ cell tumours based on serum and cerebrospinal fluid levels of tumour markers. J Clin Neurosci 8:27-30. https://doi.org/10.1054/jocn.2000.0750

22. Sawamura $\mathrm{Y}$, de Tribolet N, Ishii N, Abe H (1997) Management of primary intracranial germinomas: diagnostic surgery or radical resection? J Neurosurg 87:262-266. https://doi.org/10.3171/jns.1997.87.2.0262

23. Malone H, Yang J, Hershman DL, Wright JD, Bruce JN, Neugut Al (2015) Complications Following Stereotactic Needle Biopsy of Intracranial Tumors. World Neurosurg 84:1084-1089. https://doi.org/10.1016/j.wneu.2015.05.025

24. Grossman R, Sadetzki S, Spiegelmann R, Ram Z (2005) Haemorrhagic complications and the incidence of asymptomatic bleeding associated with stereotactic brain biopsies. Acta Neurochir (Wien) 147:627-631 discussion 631. https://doi.org/10.1007/s00701-005-0495-5

25. Shakal AA, Mokbel EA (2014) Hemorrhage after stereotactic biopsy from intra-axial brain lesions: incidence and avoidance. J Neurol Surg A Cent Eur Neurosurg 75:177-182. https://doi.org/10.1055/s-0032-1325633

26. McGirt MJ, Woodworth GF, Coon AL, Frazier JM, Amundson E, Garonzik I, Olivi A, Weingart JD (2005) Independent predictors of morbidity after image-guided stereotactic brain biopsy: a risk assessment of 270 cases. J Neurosurg 102:897-901. https://doi.org/10.3171/jns.2005.102.5.0897

27. Barkley AS, Sullivan LT, Gibson AW, Camacho D, Barber JK, Ko AL, Silbergeld DL, Ravanpay AC (2020) Stereotactic Brain Biopsy Hemorrhage Risk Factors and Implications for Postoperative Care at a Single Institution: An Argument For Postoperative Imaging. World Neurosurg 144:e807-e812. https://doi.org/10.1016/j.wneu.2020.09.084

\section{Figures}

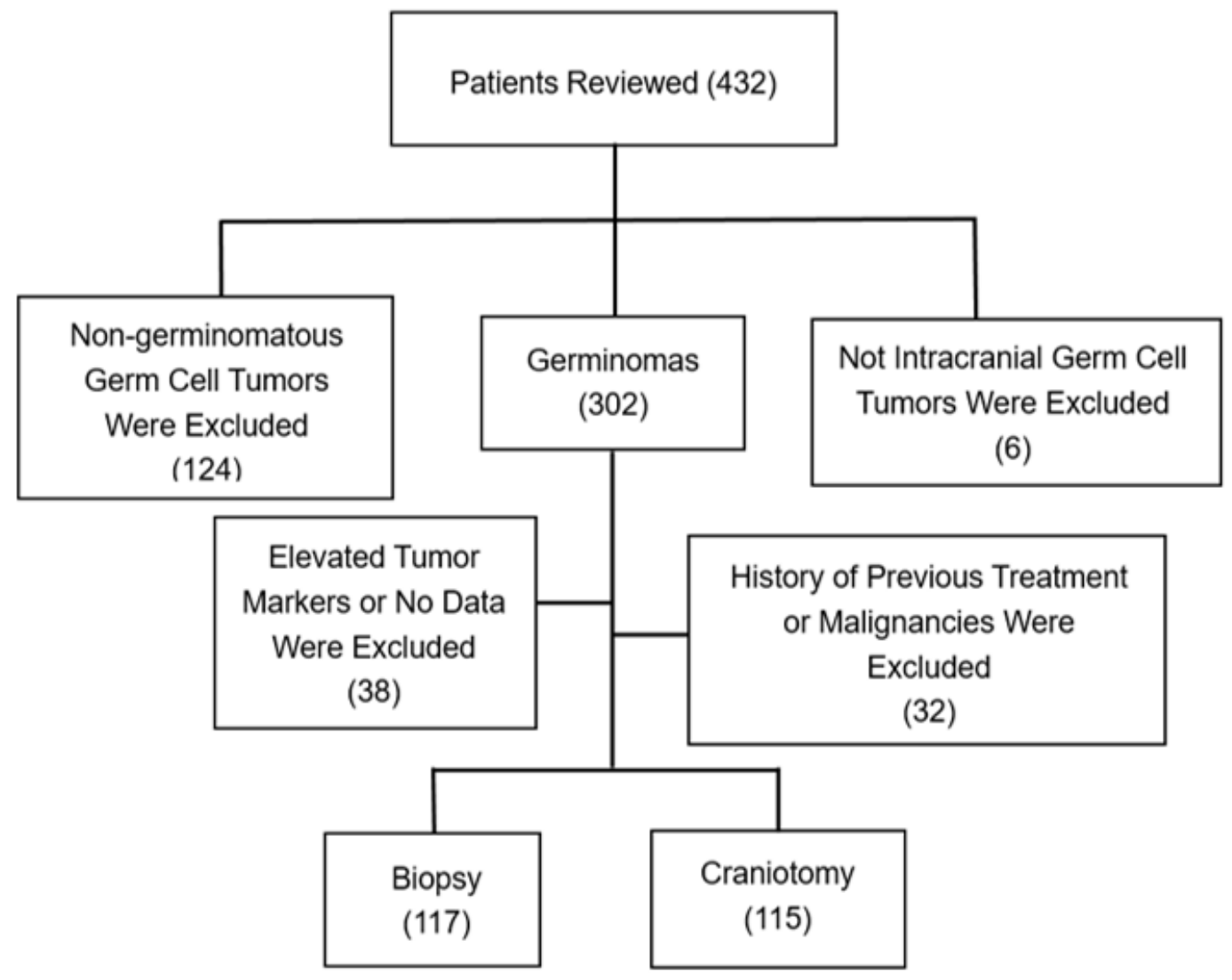

Figure 1

Page $13 / 16$ 
The procedure of patient selection based on the defined criteria was shown in a flowchart.

A

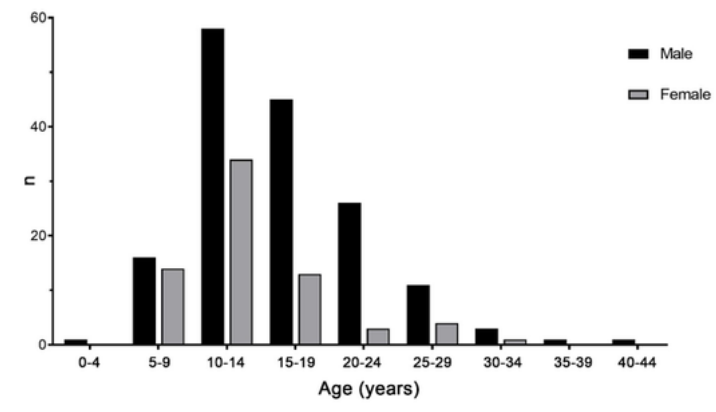

B

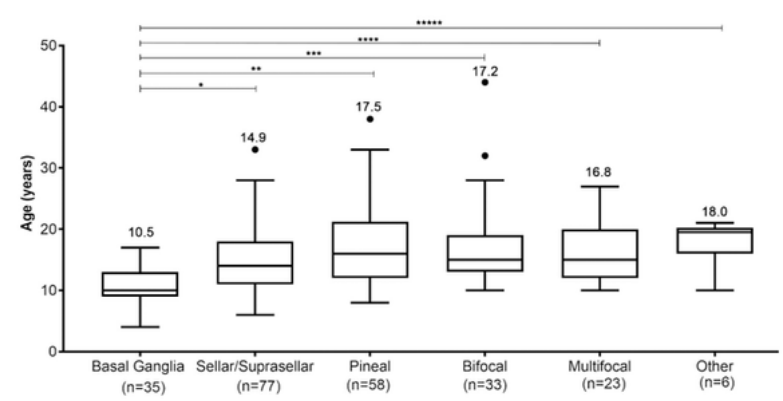

c

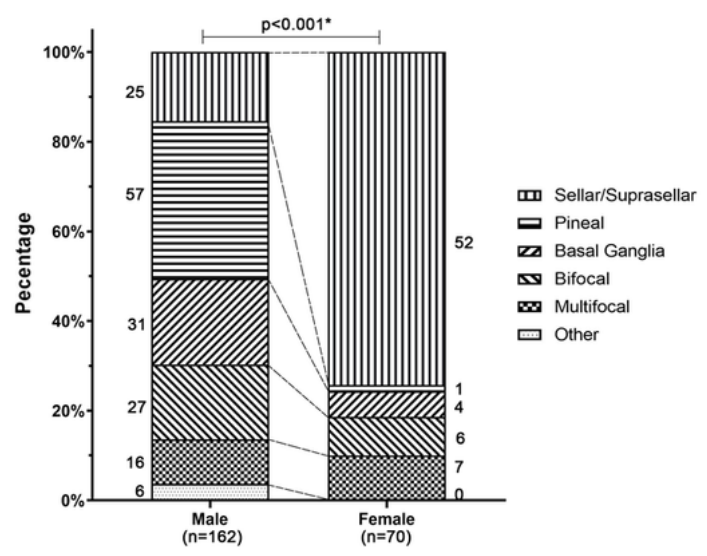

Figure 2

(A): Age distribution of intracranial germinomas patients is shown in a bar graph. Mean and median ages were 15.5 and 14 years old.

(B): The distribution of age according to tumors' locations is presented. Basal ganglia germinomas $(10.5 \pm 3.0)$ were more frequently found in younger patients compared with sellar/suprasellar region $(14.9 \pm 5.8, * P=0.001)$, pineal region $(17.5 \pm 6.5, * * P<0.001)$, bifocal region (17.2 $\left.\pm 7.0,{ }^{\star \star \star} \mathrm{P}<0.001\right)$, multifocal region $(16.8 \pm 5.2, \star \star \star \star P<0.001)$, and other regions $(18.0 \pm 4.0, \star \star \star \star \star P=0.009)$.

(C): The distribution of tumors' locations in different genders is shown. $15.4 \%$ of male patients $(n=25)$ had intracranial germinomas located in sellar/suprasellar region and 35.2\% $(n=57)$ in pineal region, $19.1 \%(n=31)$ in basal ganglia region, $16.7 \%(n=27)$ in bifocal region, 9.9\% $(n=16)$ in multifocal region, and 3.7\% $(n=6)$ in other regions. Regarding female patients, $74.3 \%(n=52)$ had germinomas in sellar/suprasellar region, $1.4 \%(n=1)$ in pineal region, $5.7 \%(n=4)$ in basal ganglia region, $8.6 \%(n=6)$ in bifocal region, and $10.0 \%$ $(n=7)$ in multifocal region $(P<0.001 *)$. 


\section{A $\beta$-HCG}

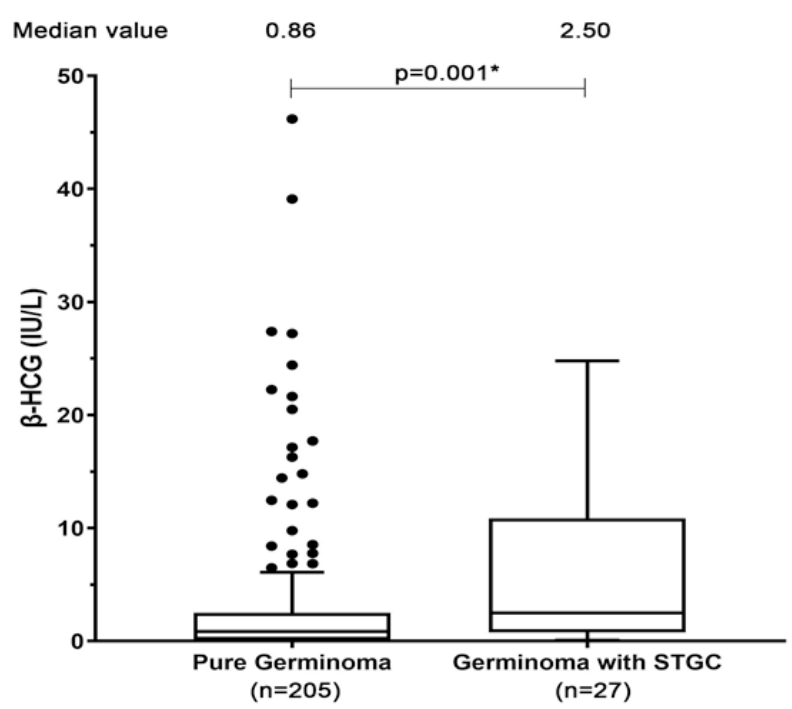

\section{B AFP}

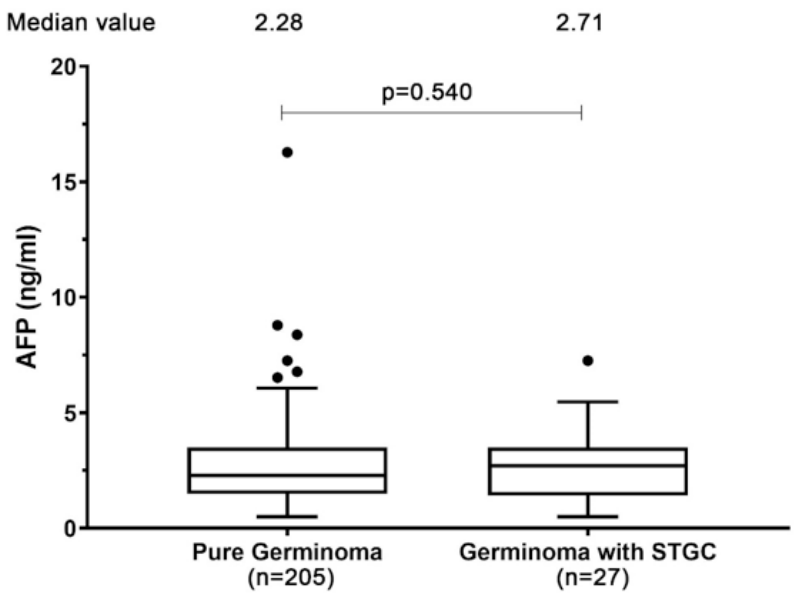

\section{Figure 3}

The serum levels of $\beta$-HCG and AFP were compared between germinoma + STGCs group $(n=27)$ and pure germinoma group $(n=205)$. Germinoma + STGCs group had a significantly higher serum level of $\beta$-HCG than pure germinoma group $\left(P<0.001^{*}\right)$ and no statistically significant difference was observed in serum AFP level $(P=0.540)$. 


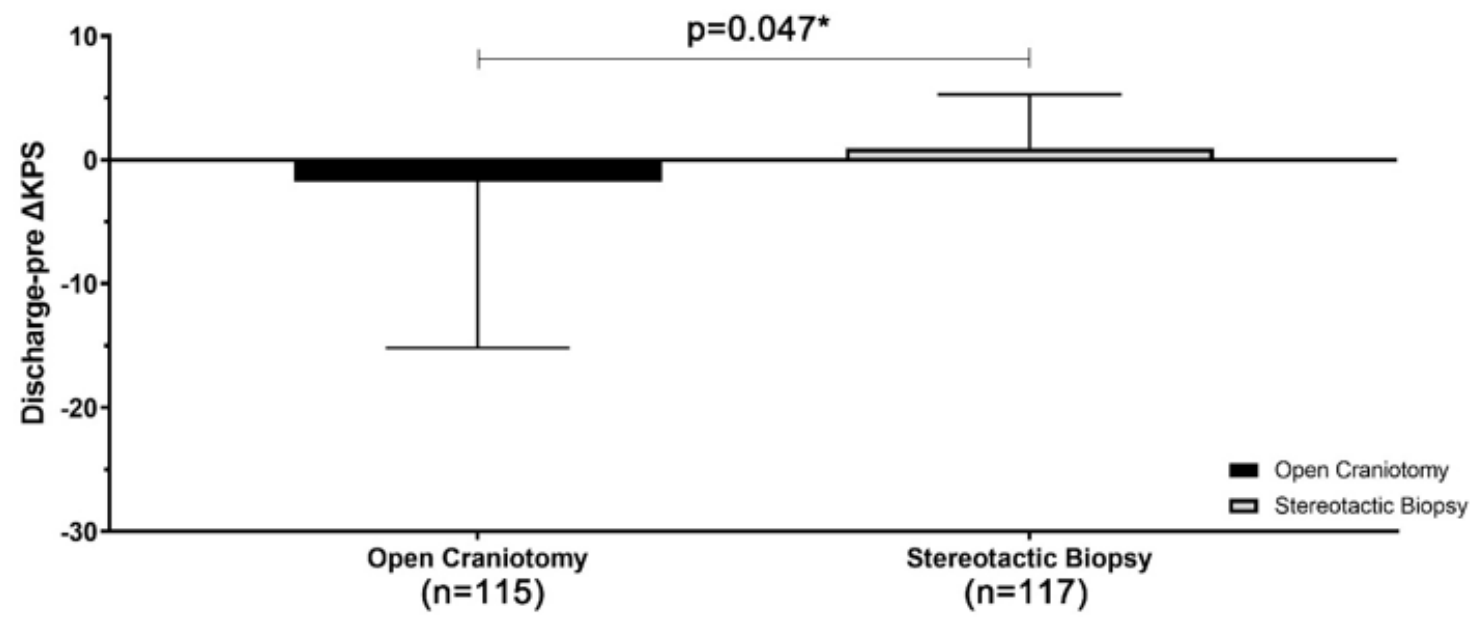

Figure 4

Comparison of discharge-pre $\triangle$ KPS in different surgical groups. Stereotactic biopsy showed increase of KPS scores at hospital discharge (0.9) in contrast to the decrease of KPS scores of open craniotomy $\left(-1.7, P=0.047^{\star}\right)$. 